Original Research Article

\title{
Efficacy and safety of a centrally acting analgesic flupirtine in primary knee osteoarthritis in comparison to tramadol: a randomized controlled trial
}

\author{
Tanmoy Kanti Goswami' ${ }^{1}$, Pradip Kumar Ghoshal ${ }^{2 *}$, Avijit Hazra ${ }^{3}$, Asish Biswas ${ }^{1}$
}

\begin{abstract}
${ }^{1}$ Department of Pharmacology,
${ }^{2}$ Department of Cardiology,

NRS Medical College, Kolkata,

West Bengal, India

${ }^{3}$ Department of Pharmacology, IPGME and R, Kolkata, West

Bengal, India
\end{abstract}

Received: 22 January 2018

Accepted: 01 February 2018

*Correspondence to:

Dr. Pradip Kumar Ghoshal, Email: pradipghosalcardiology @ gmail.com

Copyright: (C) the author(s), publisher and licensee Medip Academy. This is an openaccess article distributed under the terms of the Creative Commons Attribution NonCommercial License, which permits unrestricted noncommercial use, distribution, and reproduction in any medium, provided the original work is properly cited.

\begin{abstract}
Background: Osteoarthritis (OA) is a chronic, degenerative joint disorder responsible for considerable morbidity, particularly in old age. Flupirtine, a new centrally acting analgesic, is devoid of the adverse effects of NSAIDs and opioid analgesics. In this study author compared the effectiveness and safety of flupirtine with tramadol in knee OA.

Methods: An open label, randomized, controlled trial was done with patients of primary knee OA of both sexes, age $>50$ years. Patients were recruited from Rheumatology OPD of SSKM Hospital. A minimum WOMAC score of 35 was essential for recruitment. Patients with serious comorbidities were excluded. They were treated orally with either flupirtine (100mg thrice daily) or tramadol (50mg thrice daily) for 12 weeks.

Results: Ninety patients were recruited and data of 42 on flupirtine and 41 on tramadol were analysed. There was significant improvement in pain, stiffness and physical function compared to baseline in both the groups. However, there was no significant difference between groups at 4,8 and 12 weeks. Responder rate (50\% reduction in pain score from baseline) was $66.67 \%$ with flupirtine and $48.78 \%$ with tramadol $(\mathrm{p}=0.122)$. Flupirtine caused 4 adverse events compared to 16 with tramadol. However, both the drugs were well-tolerated.

Conclusions: The effectiveness of flupirtine in knee OA is comparable to tramadol, while causing minimal adverse effects. Long-term benefits need to be explored.
\end{abstract}

Keywords: Flupirtine, Primary osteoarthritis, Tramadol

\section{INTRODUCTION}

$\mathrm{OA}$ is the most common form of degenerative arthritis associated with significant morbidity. ${ }^{1}$ In the Framingham study. ${ }^{2} \mathrm{OA}$ has ranked equally with congestive heart failure and chronic obstructive pulmonary disease as a cause of significant disability. The disease burden in the community can well be envisaged by the fact that about $25 \%$ of adults above the age of 65 years suffer from OA. ${ }^{2}$ Its prevalence markedly increases after the age of 50 years in males and 40 years in females. ${ }^{1,2}$
Most cases of osteoarthritis have no known cause and are referred to as primary osteoarthritis. Primary osteoarthritis is mostly related to aging. It can present as localized, generalized or as erosive osteoarthritis. Secondary osteoarthritis is caused by another disease or conditions like trauma, gouty arthritis or rheumatoid arthritis. ${ }^{3}$

Primary knee OA is the common type of osteoarthritis in all racial groups. ${ }^{4}$ Pain and other symptoms of OA may have a profound effect on quality of life affecting both physical function and psychological parameters. Knee OA is not a localized disease of cartilage alone, but this is 
considered as a chronic disease of the whole joint, including articular cartilage, meniscus, ligament, and periarticular muscle that may result from multiple pathophysiological mechanisms. It is a painful and disabling disease that affects millions of patients. ${ }^{5}$ Despite its severe consequences, however, most patients with knee $\mathrm{OA}$ can be managed in the community and in primary care. $^{6}$

Current pharmacotherapy of OA is mainly directed towards symptom control by using analgesic-antiinflammatory agents, namely non-steroidal antiinflammatory drugs (NSAIDs). Pain relief in OA entails usage of NSAIDs for prolonged periods. Obviously, the high incidence of adverse effects of these agents involving the gastrointestinal, renal and cardiovascular systems often possess a significant problem. These agents however do not have any impact on disease progression. Therefore, current research is focused towards developing drugs that could relieve joint pain, joint stiffness and disability in osteoarthritis with fewer side effects. ${ }^{7-9}$

Flupirtine is a centrally acting analgesic. ${ }^{10}$ It's mechanism of action is different from opioids and NSAIDs. It is reported to have selective neuronal potassium channel opening property and N-methyl D-aspartate (NMDA) receptor antagonist activity. It also has muscle relaxant and antioxidant property. It is reported to be well-tolerated with no abuse potential and lack of withdrawal effect. ${ }^{11,12}$

Flupirtine has been recently introduced into the Indian market. Clinical trials have been conducted with this drug in different pain disorders in other countries. ${ }^{13-16}$ Since there is few published data on its efficacy and safety in Indian population, we proposed to undertake a randomized controlled trial of flupirtine in symptomatic OA of the knee joint, using the opioid-like analgesic tramadol as a comparator.

\section{METHODS}

The study was designed as a prospective, parallel group, single blind, phase-IV, randomized controlled trial. Between May 2011 to June 2012, adult above 50 years of either gender, attending the rheumatology outpatient department of SSKM Hospital, Kolkata with clinically diagnosed cases of primary early symptomatic OA affecting at least one knee joint (in case of bilateral knee involvement, the more symptomatic knee was scored as the 'signal knee') were screened. A written informed consent was obtained after screening prior to inclusion in the study. Patients having knee joint pain suffers for at least one month in the preceding three months along with morning stiffness less than 30 min or knee crepitus were included in this study. The cut off mark for the inclusion was intensity of knee pain on movement at least $35 \mathrm{~mm}$ on a $100 \mathrm{~mm}$ visual analogue scale (VAS) scale in western Ontario Macmaster universities osteoarthritis index (WOMAC). Secondary OA due to injury, inflammatory condition, metabolic or rheumatic disease; patient with organ dysfunction were excluded from the study. Patients known to have severe and advanced OA disease with joint space width $<2 \mathrm{~mm}$ or deformed joint, prior intra-articular injection of hyaluronic acid / steroid / joint lavage in the study knee any time in the past three months were also excluded from the study.

Patients were advised to take one capsule three times daily. Subjects were randomized in blocks of 20 in 1:1 ratio using WinPepi (version 10.1, 2010) software. There was no stratification. Each subject underwent five study visits, namely screening, baseline, 4 weeks and 8 weeks followup and end-of-study visits.

Each patient was treated for 12 weeks. The severity of osteoarthritis was assessed by WOMAC osteoarthritis index (3.1 version) and clinical global impression (CGI) score. In WOMAC Osteoarthritis Index pain, stiffness and physical function were measured on $100 \mathrm{~mm}$ VAS scale $(0$ denoting no sign/symptom and 100 worst possible sign/symptom) and this index was calculated in every visit from screening to end of study visit.

CGI score was assessed based on a 5-point likert scale at each follow up visits and at the end of study. In CGI, grade 0 denoted as much worsened condition and grade 4 denoted as greatly improved condition. Safety was evaluated at each visit by taking thorough history and conducting clinical examination. Complaints of the patient as well as adverse events noted by the investigators were recorded as treatment emergent adverse events. In addition, routine blood counts and tests of hepatorenal function were done at baseline and at study end. Compliance with study medication was assessed through the pill count method at the $4^{\text {th }}$ and $8^{\text {th }}$ week follow up and end of study.

Sample size estimation was done on the basis of responder rate. In this study responder rate was defined as subject with 50\% reduction of pain score in WOMAC OA index in comparison to base line. It was estimated that 39 subjects would be required per group in order to detect a $30 \%$ difference in responder rate (considering $50 \%$ as the probable rate for tramadol) with $80 \%$ power and $5 \%$ probability of type 1 error. Assuming a 20\% dropout rate, the recruitment target was being set as 49 subjects per group or 98 overall.

\section{Stastical analysis}

Data was summarized by routine descriptive statistics. Numerical variables had been compared between groups by Student's t test and repeated measures ANOVA was used to compare change in numerical variables over time within a group. Fisher's exact test had been employed for intergroup comparison of categorical variables. All analyses were 2-tailed and $\mathrm{p}<0.05$ was considered to be statistically significant. Graph Pad Prism version 5.0 (San Diego, California: Graph Pad Software Inc., 2007) and Statistica version 6 (Tulsa, Oklahoma: Stat Soft Inc., 2001) software were used for statistical analysis. 


\section{RESULTS}

Ninety patients were recruited and randomized in to two groups of which 42 subjects on flupirtine and 41 subjects on tramadol were analysed. Modified intention to treat approach has been followed here. Figure 1 depicts the flow of study participants. As seen from Table 1, demography characteristics were comparable in the two groups. The changes in pain, stiffness and physical function in WOMAC OA index and responder rate in both the groups are depicted (Table 2, 3).

Table 1: Age and sex distribution of the study population.

\begin{tabular}{|c|c|c|c|}
\hline Parameter & $\begin{array}{l}\text { Flupirtine } \\
(n=42)\end{array}$ & $\begin{array}{l}\text { Tramadol } \\
(n=41)\end{array}$ & $\begin{array}{l}\mathbf{p} \\
\text { value }\end{array}$ \\
\hline \multicolumn{3}{|l|}{ Age (years) } & \multirow{4}{*}{0.341} \\
\hline Range & $50-73$ & $50-73$ & \\
\hline Mean \pm SD & $56.1 \pm 8.30$ & $55.9 \pm 6.22$ & \\
\hline Median (IQR) & $55(52-58)$ & $54(51-58)$ & \\
\hline \multicolumn{3}{|l|}{ Sex } & \multirow{3}{*}{1.000} \\
\hline Male & $28(66.67 \%)$ & $28(68.29 \%)$ & \\
\hline Female & $14(33.33 \%)$ & $13(31.71 \%)$ & \\
\hline
\end{tabular}

$\mathrm{SD}=$ Standard deviation; $\mathrm{IQR}=$ interquartile range, $\mathrm{p}$ value in the last column is from intergroup comparison by Man-Whitney $\mathrm{U}$ test for age and Fisher's exact test for sex distribution.

Table 2: Comparison of efficacy variables between groups and within groups over the 12 -week treatment period.

\begin{tabular}{|c|c|c|c|}
\hline Parameter & Flupirtine & Tramadol & p-value \\
\hline \multicolumn{4}{|c|}{ Pain in WOMAC (VAS) } \\
\hline Baseline & $294.7 \pm 65.20$ & $280.5 \pm 65.53$ & 0.324 \\
\hline End-of-trial & $148.7 \pm 75.85$ & $177.1 \pm 76.71$ & 0.094 \\
\hline \multicolumn{4}{|c|}{ Stiffness in WOMAC (VAS) } \\
\hline Baseline & $40.9 \pm 30.74$ & $39.9 \pm 31.02$ & 0.888 \\
\hline End-of-trial & $19.6 \pm 17.66$ & $21.9 \pm 22.57$ & 0.620 \\
\hline \multicolumn{4}{|c|}{ Physical function in WOMAC (VAS) } \\
\hline Baseline & $815.9 \pm 130.73$ & $782.3 \pm 135.32$ & 0.253 \\
\hline End-of-trial & $521.1 \pm 192.37$ & $599.0 \pm 195.12$ & 0.070 \\
\hline
\end{tabular}

Within group $\mathrm{p}$ value- $<0.001$

Table 3: Comparison of responder rate between groups over the 12-week treatment period.

\begin{tabular}{|llll|}
\hline Drug & Responders & Non-responders & p-value \\
\cline { 1 - 3 } Flupirtine & $28(66.67 \%)$ & $14(33.33 \%)$ & 0.122 \\
\cline { 1 - 3 } Tramadol & $20(48.78 \%)$ & $21(51.22 \%)$ & \\
\hline
\end{tabular}

Responder implies at least $50 \%$ reduction in pain score from base line. $\mathrm{p}$ value in the last column is from intergroup comparison by Fisher's exact test.

In respect to pain, stiffness and physical function significant improvements were observed in both the groups at the study end compared to base line. But there was no difference between groups at any time point of study. Responder rates were $66.67 \%$ and 48.78 in flupirtine group and tramadol group respectively. The difference is not statistically significant. Table 4 depicts number of subjects had received rescue medication in both the groups. Again, the difference is not statistically significant. Comparison of CGI score between groups over the 12-week treatment period is depicted (Table 5).

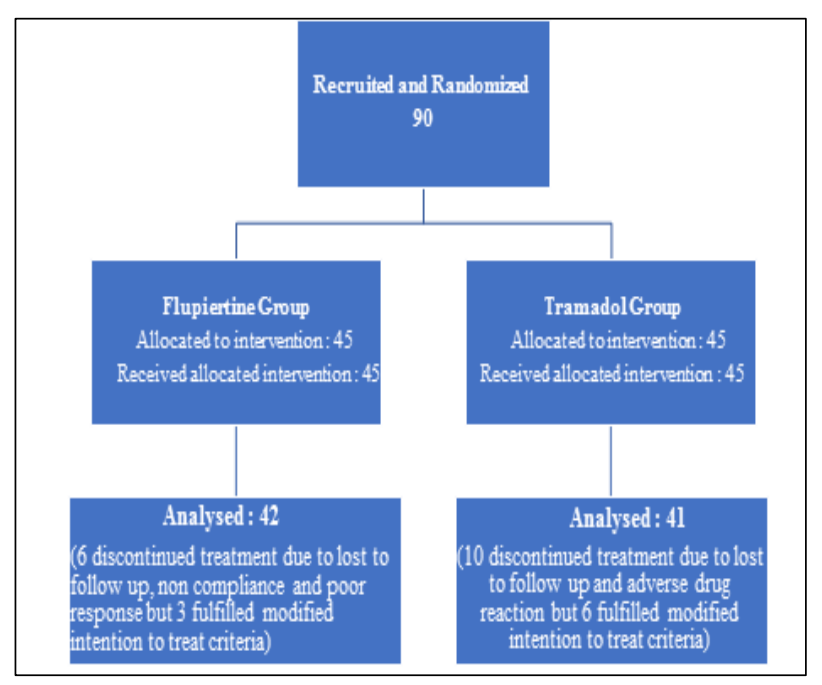

Figure 1: Flow of patients in two study arms.

Table 4: Number of subjects had rescue medication in individual groups.

\begin{tabular}{|llll|}
\hline Drug & Subject & P-value \\
\hline & $\begin{array}{l}\text { Rescue } \\
\text { medication }\end{array}$ & $\begin{array}{l}\text { Without rescue } \\
\text { medication }\end{array}$ & \\
\hline Flupirtine & $12(28.57 \%)$ & $30(71.43 \%)$ & \\
\cline { 1 - 3 } Tramadol & $14(34.15 \%)$ & $27(65.85 \%)$ & 0.640 \\
\hline
\end{tabular}

$\mathrm{p}$ value in the last column is from intergroup comparison by Fisher's exact test.

Table 5: Comparison CGI score between groups over the 12-week treatment period.

\begin{tabular}{|c|c|c|c|}
\hline Parameter & Flupirtine & Tramadol & $\begin{array}{l}p \text { - } \\
\text { value }\end{array}$ \\
\hline \multicolumn{4}{|l|}{ Follow-up 1} \\
\hline CGI-2 & $9(21.43 \%)$ & $18(43.90 \%)$ & \multirow{3}{*}{0.072} \\
\hline CGI-3 & $28(66.67 \%)$ & $21(51.22 \%)$ & \\
\hline CGI-4 & $5(11.90 \%)$ & $2(4.885)$ & \\
\hline \multicolumn{4}{|l|}{ Follow-up 2} \\
\hline CGI-2 & $7(16.67 \%)$ & $12(30 \%)$ & \multirow{3}{*}{0.127} \\
\hline CGI-3 & $28(66.67 \%)$ & $26(65 \%)$ & \\
\hline CGI-4 & $5(11.90 \%)$ & $2(5 \%)$ & \\
\hline \multicolumn{4}{|l|}{ End-of-trial } \\
\hline CGI-2 & $5(11.90 \%)$ & $13(31.71 \%)$ & \multirow{3}{*}{0.012} \\
\hline CGI-3 & $20(47.62 \%)$ & $22(53.66 \%)$ & \\
\hline CGI-4 & $17(40.48 \%)$ & $6(14.63 \%)$ & \\
\hline
\end{tabular}

CGI = clinical global impression scale $($ CGI-2 $=$ no change, CGI$3=$ improved, CGI- $4=$ greatly improved). Follow-up visits 1 and 2 are 4 weeks and 8 weeks and end-of-study visit is 12 weeks from commencement of study medication. $\mathrm{p}$ value in the last column is from intergroup comparison by Chi-square test. 


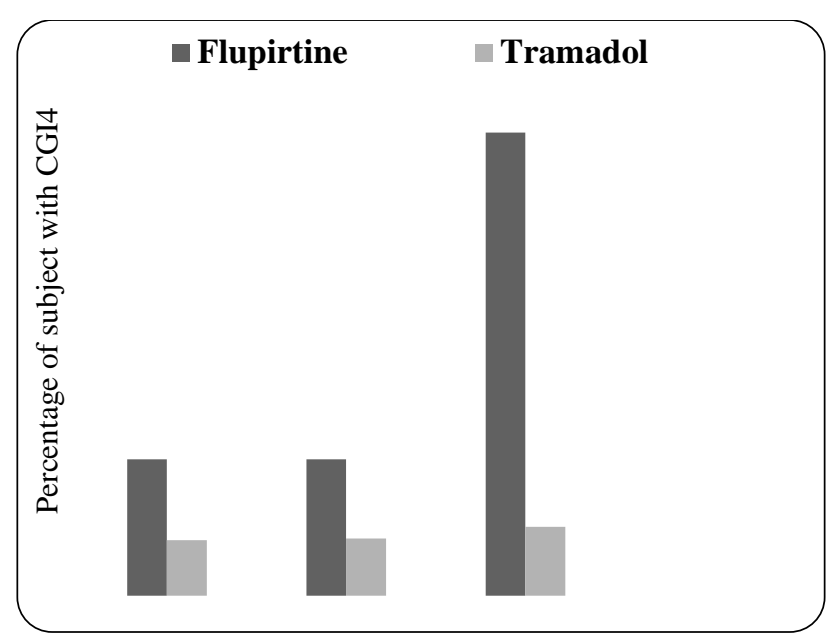

\section{Figures 2: Percentage of subjects with clinical global impression (CGI) rating of 4 .}

There is no significant difference between groups at follow-up 1 and follow-up 2 visits. However, a significant difference is observed at the study end. Figure 2 depicts percentage of subjects with CGI rating of 4 (i.e. much improved) at 4 weeks and 8 weeks from the commencement of study medication and at the end-ofstudy visit.

Table 6 depicts the various treatment emergent adverse events observed in the study population. Most were mild to moderate in severity. Sixteen adverse events were observed in tramadol group and four in the flupirtine group. The difference in frequency between the two groups was not statistically significant for any of particular events. There were no hospitalizations and serious adverse events during the study.

Table 6: Frequencies of individual adverse events in the two study groups.

\begin{tabular}{|lll|}
\hline Adverse events & Flupirtine & Tramadol \\
\hline Nausea & 0 & 4 \\
\hline Constipation & 0 & 2 \\
\hline Dyspepsia & 0 & 2 \\
\hline Drowsiness & 2 & 1 \\
\hline Dizziness & 1 & 3 \\
\hline Weakness & 0 & 1 \\
\hline Rise of liver enzymes & 1 & 0 \\
\hline Vomiting & 0 & 2 \\
\hline Diarrhea & 0 & 1 \\
\hline
\end{tabular}

The difference in frequency between the two groups was not statistically significant for any of the events by Fisher's exact test.

\section{DISCUSSION}

Flupirtine is a centrally acting analgesic which was approved by DCGI in India in the year 2010. ${ }^{13}$ Only few studies have been conducted with flupirtine for prolonged period. Osteoarthritis is a chronic non-inflammatory condition of joints which is a great financial burden to the society and country. Pathogenesis and mechanism of development of OA are not very clear. Knee OA is a common variety of OA. Females are more susceptible to knee osteoarthritis and it appears early in female. In this study $66.67 \%$ subjects in flupirtine group and $68.29 \%$ subjects in tramadol group were female.

There were three efficacy variables in this study i.e. pain, stiffness and physical function in WOMAC index; responder rate as $50 \%$ reduction of pain score from the baseline and physician-rated clinical global impression scale (CGI). In WOMAC index pain, stiffness and physical function were measured with visual analogue scale (VAS). These measures are frequently used in randomized controlled trials in OA.

Head to head comparison between tramadol and flupirtine have been conducted in few clinical trials. A parallel group double blind randomized controlled study comparing flupirtine with tramadol was done to evaluate the efficacy in reducing symptoms in low back pain. This study concluded that flupirtine and tramadol were equally effective in reducing pain. Flupirtine was better tolerated than tramadol. ${ }^{14}$ In another recently conducted study, flupirtine modified release (MR) formulation (400mg) in once daily dosage was compared with placebo and tramadol extended release (ER) formulation $(200 \mathrm{mg}$ ) in once daily dosage for the management of moderate to severe chronic low back pain. Results suggested that flupirtine MR was non-inferior when compared with tramadol ER and superior when compared with placebo. Flupirtine MR was associated with a significantly lower incidence of treatment emergent adverse events than tramadol ER and exhibited an overall safety and tolerability profile non-inferior to placebo. ${ }^{15}$ But limitation of both studies was the short duration of treatment. In contrast, the treatment duration of our study was 12 weeks.

This study had its share of limitations. Blinding could not be possible in this study for logistical reasons. Blinding is necessary to prevent ascertainment bias. There was lack of placebo control in this study which makes it difficult to differentiate between a true treatment related improvement and pain relief due to natural fluctuating course of disease. Present study concluded that there was no difference between flupirtine and tramadol in reducing pain, stiffness and improving physical functions in knee OA. There was no significant difference between groups in respect to responder rate. But in GGI scale, flupirtine was better than tramadol in reducing symptoms at study end and the drug was well tolerated.

\section{ACKNOWLEDGEMENTS}

Authors would like to thank Prof. Alakendu Ghosh, for his encouragement and permission to access patients in his department. Author are also thankful to Prof. Pradip 
Kumar Mitra, Former Director, IPGME\&R, for enabling the necessary logistical support for the study.

Funding: No funding sources

Conflict of interest: None declared

Ethical approval: The study was approved by the Institutional Ethics Committee (CTRI/2017/10/010142)

\section{REFERENCES}

1. Breedveld FC. Osteoarthritis - the impact of a serious disease. Rheumatol. 2004;43:i4-8.

2. Guccione AA, Felson DT, Anderson JJ, Anthony JM, Zhang Y, Wilson PW, et al. The effects of specific medical conditions on the functional limitation of elders in the Framingham study. Am J Public Health. 1994;84:35-8.

3. Dicesare PE, Abramson SB. Pathogenesis of osteoarthritis. In: Harris ED, Budd RC, Genovese $\mathrm{MC}$, et al, editors. Kelley's Textbook of Rheumatology. $7^{\text {th }}$ Ed. Elsevier Saunders; 2005:14931513.

4. Doherty M, Ralston SH. Musculoskeletal diseases. In: Davidson's principles and practice of medicine. Colledge NR, et al, editors. $21^{\text {st }}$ Ed. Elsevier; 2010:1083-1103.

5. Hayami T. Osteoarthritis of the knee joint as a cause of musculoskeletal ambulation disability symptom complex (MADS). Clin Calcium. 2008;18:1574-80.

6. Peat G, McCarney R, Croft P. Knee pain and osteoarthritis in older adults: a review of community burden and current use of primary health care. Ann Rheum Dis. 2001;60:91-7.

7. Rintelen B, Neumann K, Leeb BF. A meta-analysis of controlled clinical studies with diacerein in the treatment of osteoarthritis. Arch Intern Med. 2006;166:1899-906.

8. Sun BH, Wu CW, Kalunian KC. New developments in osteoarthritis. Rheum Dis Clin North Am. 2007;33:135-48.
9. Fidelix TS, Soares BG, Trevisani VF. Diacerein for osteoarthritis. Cochrane database Syst Rev. 2006;25:CD005117.

10. McMahon FG, Arndt WF Jr, Newton JJ, Montgomery PA, Perhach JL. Clinical experience with flupirtine in the US. Postgrad Med J. 1987;63(3):81-5.

11. Müller-Limmroth W. The effect of a new analgesic, flupirtine, on psychomotor performance in humans. Arzneimittelforschung. 1985;35:1089-92.

12. Heusinger JH. Efficacy and tolerance of flupirtine and pentazocine in two multicentre trials. Postgrad Med J. 1987;63:71-9.

13. List of approved drugs from 01 January 2010 to $31^{\text {st }}$ December 2010. Available at: http://cdsco.nic.in /list $\% 20$ of $\% 20$ approved $\% 20$ drug $\% 20$ from $\% 2001$.ht m. Accessed 30 September 2012.

14. Li C, Ni J, Wang Z, Li M, Gasparic M, Terhaag B, et al. Analgesic efficacy and tolerability of flupirtine vs. tramadol in patients with subacute low back pain: a double-blind multicentre trial. Curr Med Res Opin. 2008;24:3523-30.

15. Überall MA, Mueller-Schwefe GH, Terhaag B. Efficacy and safety of flupirtine modified release for the management of moderate to severe chronic low back pain: results of SUPREME, a prospective randomized, double-blind, placebo-and activecontrolled parallel-group phase IV study. Curr Med Res Opin. 2012;28(10):1617-34.

Cite this article as: Goswami TK, Ghoshal PK, Hazra A, Biswas A. Efficacy and safety of a centrally acting analgesic flupirtine in primary knee osteoarthritis in comparison to tramadol: a randomized controlled trial. Int J Basic Clin Pharmacol 2018;7:381-5. 